\title{
EXPLICANDO EL ACTIVISMO DE LOS MIEMBROS DE LAS ORGANIZACIONES JUVENILES DE LOS PARTIDOS POLÍTICOS ESPAÑOLES. ENTRE LA TEORÍA DE LA ELECCIÓN RACIONAL Y EL MODELO DE INCENTIVOS GENERALES
}

\section{Explaining the activism of the members of the youth sections of Spanish political parties. Between rational choice theory and general incentives model}

\author{
FRANCISCO JAVIER ALARCÓN GONZÁLEZ \\ Universidad de Jaén \\ falarcon@ujaen.es
}

Cómo citar/Citation

Alarcón González, F. J. (2021).

Explicando el activismo de los miembros de las organizaciones juveniles de los partidos políticos españoles. Entre la teoría de la elección racional y el modelo de incentivos generales.

Revista de Estudios Políticos, 191, 287-321.

doi: https://doi.org/10.18042/cepc/rep.191.10

\section{Resumen}

Este trabajo tiene por objetivo profundizar en las explicaciones del comportamiento político, en términos de activismo político, de los miembros de las organizaciones juveniles de los partidos políticos españoles. Se analizan los condicionantes de la participación política relacionada con el activismo en el seno de tres fuerzas políticas. El trabajo parte de la teoría de la elección racional, que tiene en cuenta las evaluaciones individuales sobre potenciales costes y beneficios del activismo y se completa con el modelo de incentivos generales de Seyd y Whiteley (1992), que recoge aquellas variables no compatibles con los presupuestos de la elección racional. El análisis señala que el modelo funciona relativamente bien en términos de varianza explicada. Pero también muestra cómo ciertas variables que explican el compromiso entre los miembros de los partidos tales como los incentivos de proceso, los incentivos ideológicos, la norma social y la eficacia política grupal no influyen en el activismo de los jóvenes, con algunas excepciones entre los miembros de las diferentes formaciones políticas. El activismo juvenil partidista está influenciado por la eficacia política personal y el factor afectivo. 


\section{Palabras clave}

Comportamiento político; acción racional; incentivos generales; miembros de los partidos políticos; organizaciones juveniles.

\section{Abstract}

This paper focuses on the determinants of political behaviour, in terms of political activism, among Spanish youth section party members. The determinants of political participation related to activism within three political forces are analysed. This work starts from rational choice theory, that takes into account the individual evaluations on the potential costs and benefits from activism, and this model is compared with the explanation of General Incentives Model proposed by Seyd and Whiteley (1992), which includes variables that are not compatible with the rational choice perspective. Data show that the general incentives model works relatively well in terms of explained variance. But at the same time, determinants of party activism such a process incentives, ideological incentives, social norm, and group political efficacy do not influence youth activism, with some exceptions across members of the different political organisations analysed. Youth party activism is driven by individual political efficacy and affective factors.

\section{Keywords}

Political behaviour; rational choice; general incentives model; party members; youth sections. 


\section{SUMARIO}

I. INTRODUCCIÓN. II. LA EXPLICACIÓN DEL ACTIVISMO COMO COMPORTAMIENTO POLÍTICO: ELECCIÓN RACIONAL E INCENTIVOS GENERALES: 1. Modelo de elección racional. 2. Modelo de incentivos generales. III. DATOS. IV. EL ACTIVISMO DE LOS MIEMBROS DE LOS PARTIDOS POLÍTICOS: EL TIEMPO DEDICADO A ACTIVIDADES PARTIDISTAS. V. LAS VARIABLES INDEPENDIENTES DE LOS MODELOS EXPLICATIVOS DEL ACTIVISMO: 1. El modelo de elección racional básico. 2. El modelo de elección racional ampliado. 3. El modelo de incentivos generales. VI. LOS INCENTIVOS EN LOS MIEMBROS DE LAS ORGANIZACIONES JUVENILES: SIMILITUDES Y DIFERENCIAS. VII. ANÁLISIS Y DISCUSIÓN DE LOS MODELOS EXPLICATIVOS DEL ACTIVISMO. VIII. CONCLUSIONES. BIBLIOGRAFíA. ANEXO.

\section{INTRODUCCIÓN}

¿Por qué algunas personas son miembros de partidos políticos? Y una vez que son miembros, ¿por qué algunos son más activos que otros? La respuesta a estas preguntas ha sido planteada por un gran número de investigadores bajo la paradoja de la participación formulada por Olson (1965). Él argumenta que no hay ningún motivo racional para convertirse en miembro de una organización o formación política, y mucho menos para ser activo dentro de ella. Una persona puede estar completamente de acuerdo con los objetivos, pero, sin embargo, puede dejar todas las actividades y acciones en manos de otros. Bajo esta lógica, las actividades que realizan esta u otra persona rara vez son decisivas para el éxito de la formación política. De ahí su falta de implicación y, por tanto, opte por no participar. Para salvar esta paradoja, Seyd y Whiteley proponen una explicación denominada modelo de incentivos generales, que aplican en Reino Unido a los miembros del partido Conservador, Laborista y Liberal (Seyd y Whiteley, 1992, 2002; Whiteley et al., 1994a, 1994b; Whiteley y Seyd, 1996, 2002; Whiteley et al., 2006).

El modelo de incentivos generales ayuda a explicar no solo por qué se produce la unión al partido político ${ }^{1}$, sino que va más allá al arrojar luz sobre

1 Sobre la aplicación del modelo de incentivos generales al acto de afiliación puede verse el seminal trabajo de Seyd y Whiteley (1992:56-85) o las últimas publicaciones sobre los partidos políticos británicos (Poletti et al., 2019) o sobre los miembros de las 
el activismo de algunos de sus miembros y la desmovilización de otros (Seyd y Whiteley, 1992), y es bastante útil en la explicación de los niveles de participación en diferentes contextos y países (Van Haute y Gauja, 2015: 8). A pesar de estos avances y de su poder explicativo, el modelo, hasta donde conocemos, no ha sido aplicado para explicar el activismo en el contexto particular de los miembros de los partidos políticos españoles ni tampoco se ha evaluado su idoneidad en el marco de las organizaciones juveniles de los partidos políticos, tanto en las sociedades occidentales como en España ${ }^{2}$. Este trabajo pretende paliar estas dos situaciones y tiene por objetivo principal validar el modelo de incentivos generales para la explicación del comportamiento político de alta implicación, respondiendo a las siguientes cuestiones: ¿por qué hay miembros en las organizaciones juveniles de los partidos políticos más activos que otros?, y ¿qué variables influyen en ese activismo? El objetivo es examinar las motivaciones del activismo, con el fin último de explicar por qué algunos jóvenes son pasivos en sus formaciones políticas mientras que otros mantienen altos niveles de actividad. Se asume que el modelo de incentivos generales puede ser aplicado a los miembros de las organizaciones juveniles, pero el ajuste se verá influido por la propia naturaleza y composición de las organizaciones juveniles partidistas.

Asumimos que los incentivos y motivaciones serán las mismas para los miembros más jóvenes que para los mayores en términos de activismo, pero con diferencias que derivan de las situaciones que singularizan a las organizaciones juveniles y a sus miembros. Hay que tener en cuenta, en primer lugar, que la organización juvenil es subsidiaria del partido político, lo que supone que la presencia o disponibilidad de algunos incentivos selectivos por parte de la organización juvenil, como veremos, es más limitada. En segundo lugar, algunas organizaciones políticas juveniles permiten a sus miembros formar parte del partido político, lo que se conoce como doble militancia. A partir de su mayoría de edad, el joven además de ser miembro de la organización juvenil puede solicitar su ingreso en el partido político y formar parte de ambas

juventudes del Partido Socialdemócrata de Alemania (Weber, 2018). En este trabajo se utiliza el modelo de incentivos generales para explicar el activismo, ya que como sostienen Seyd y Whiteley (1992: 60) es más probable que los incentivos motiven para ser activos que para propiciar la afiliación. La justificación reside en dos supuestos: a) algunos miembros permanecen inactivos, lo que supone que no reciben estos beneficios, $\mathrm{y}$ b) para que los incentivos tengan efecto sobre la unión se requiere tener conocimiento previo.

2 Los trabajos sobre los miembros de los partidos políticos españoles son muy escasos y se han centrado en su mayoría en delegados congresuales. Para un estado de la cuestión, véase Baras et al. (2015). 
organizaciones con las obligaciones y ventajas derivadas de cada una de sus afiliaciones. En tercer lugar, los jóvenes se encuentran en un período transicional, se mueven de adolescentes a adultos, donde las opiniones e identidades se están desarrollando. Los jóvenes están creando su orientación política, influenciada por su familia y amigos (Eulau et al., 1959; Campbell, 1980) y se están preparando para el mercado laboral, tomando decisiones que afectarán a su futuro (Weber, 2018). También se observa en algunos casos la política como un espacio donde poder desarrollar una carrera profesional, tanto en el ámbito de la representación política (Hooghe et al., 2004) como en el sector público (Bruter y Harrison, 2009). Estas razones plantean que el conjunto de incentivos y motivaciones para el activismo entre los jóvenes requiere una atención especial.

Tras esta introducción, el artículo se estructura del siguiente modo. El próximo apartado está dedicado a la revisión teórica de los modelos propuestos para explicar el comportamiento político dentro de los partidos políticos. En él se hace una revisión de la literatura que recoge la formulación teórica que los sustenta. En el tercer apartado se presentan los datos. El cuarto epígrafe está dedicado a la variable dependiente, y se analiza el nivel de activismo en función del tiempo dedicado a la realización de actividades políticas. Tras él, en el epígrafe quinto, se explican las variables independientes de las diferentes propuestas explicativas. Posteriormente, en los epígrafes sexto y séptimo se analizan los datos, mostrando las similitudes y diferencias entre las diferentes formaciones políticas y, a través de un análisis de regresión, discutiendo en ambas secciones los principales hallazgos. El texto finaliza con unas conclusiones.

\section{LA EXPLICACIÓN DEL ACTIVISMO COMO COMPORTAMIENTO POLÍTICO: ELECCIÓN RACIONAL E INCENTIVOS GENERALES}

La teoría de la elección racional constituye el punto de partida al ser sus presupuestos recuperados en la formulación del modelo de incentivos generales. En los siguientes subepígrafes se presentan los postulados teóricos que sustentan ambos modelos y su implicación en la explicación del activismo de los miembros de los partidos políticos en general, y de las organizaciones juveniles en particular.

\section{MODELO DE ELECCIÓN RACIONAL}

Este modelo está asociado a los desarrollos teóricos de Anthony Downs (1957) y Mancur Olson (1965) y propugna un proceso de cálculo racional que intenta mostrar que, en determinadas situaciones sociales, los individuos 
tratan de maximizar sus recompensas y minimizar sus costes, a semejanza de las situaciones que ocurren en economía entre los actores del mercado. Normalmente, la investigación empírica con modelos de elección racional se ha aplicado a la participación política electoral, que supone una actividad de bajo coste (Aldrich, 1993), siendo en cambio más apropiado su empleo con miembros de los partidos políticos, ya que su decisión requiere de un mayor compromiso y no es tan trivial (Olson, 1965; Seyd y Whiteley, 1992). Olson argumentaba que los bienes públicos son inadecuados para motivar la contribución de los individuos a la acción. Dos justificaciones sustentan esta tesis: el uso de los bienes es compartido por todos y la influencia que tiene un ciudadano con su participación es muy limitada. Por lo tanto, si la contribución a realizar es escasa y, participando o no, se podrá disfrutar igualmente de los beneficios derivados de la acción, lo natural será optar por no participar. Aun así, desafiando este razonamiento, se observa que ciertos individuos participan de forma voluntaria. Esto hace que nos planteemos la explicación más allá de los beneficios públicos. La justificación dada por Olson (1965: 133) y un gran número de autores lleva a establecer la presencia de otro tipo de estímulos llamados incentivos selectivos, ya sean tangibles o inmateriales (Clark y Wilson, 1961; Clarke et al., 1978; Panebianco, 1990; Seyd y Whiteley, 1992).

Nos encontramos con dos modelos basados en los presupuestos de la elección racional: una versión simple y otra extendida donde se tienen en cuenta los incentivos selectivos. En la versión simple, el activismo reposa sobre una ecuación donde las variables que intervienen son la percepción de su influencia o eficacia política personal, derivada de la participación en política más el beneficio colectivo resultante de la acción menos el coste individual de contribuir al bien colectivo.

La eficacia politica personal está arraigada en la realidad objetiva del sujeto. Si este percibe eficacia personal, se debe a la capacidad de influir de forma objetiva en los beneficios colectivos. Estos, beneficios colectivos y eficacia política individual, serán iguales tanto para los miembros del partido político como para los de la organización juvenil y serán percibidos como altos. Hay que señalar que altos valores de eficacia personal están relacionados con la participación política y así ha sido señalado por la literatura (Clarke y Acock, 1989). Se espera que altos valores de eficacia política entre los jóvenes se relacionen con un mayor activismo. El coste para el individuo de contribuir al bien colectivo mediante su participación opera en dos niveles, el del tiempo y el del dinero. Es decir, la percepción que tiene el miembro de la formación política juvenil de que su participación es costosa y requiere de tiempo. Es de suponer que la influencia del coste de participación en el activismo de los miembros de las organizaciones es baja. La explicación de percibir bajos costes en la participación deriva de su momento vital, al encontrarse por edad en un momento 
de flexibilidad, en términos de tiempo y cargas familiares. Gran parte de ellos se encuentran formándose y sin cargas familiares (Alarcón, 2017), lo que les hace disponer de más tiempo libre que posibilita el activismo partidista (Verba et al., 1995).

La versión extendida del modelo de elección racional distingue dentro de los beneficios entre aquellos que podemos considerar colectivos y los incentivos selectivos, que tienen un carácter más privativo o individual. Estos incentivos ofrecidos por los partidos políticos afectan al comportamiento en el seno de cada organización política (Clark y Wilson, 1961: 130). Su incorporación supone distinguir entre incentivos de resultado, incentivos de proceso e incentivos ideológicos (Seyd y Whiteley, 1992). Estos tres incentivos son aplicables tanto por el partido político como por la organización política juvenil, aunque con ciertas matizaciones.

Los incentivos de resultado recogen el impacto de «private returns from participation associated with building a political career as an elected representative of the party» (Whiteley et al., 1994b: 85), o en otras palabras, con la posibilidad de alcanzar cierto estatus político (Patie et al., 2004: 157). Hay que señalar que los partidos políticos disponen de cierta discrecionalidad para ejercer este incentivo. Las posiciones políticas normalmente son en cargos de representación, en la jerarquía organizativa del partido, como empleado del partido político o en alguna agencia, entre otras posibilidades. Los jóvenes miembros pueden ver el partido político como un puente hacia posiciones laborales en política como cargo público o en el propio partido (Bruter y Harrison, 2009: 19-20), o incluso fuera de la política (Espinoza y Madrid, 2010: 97) en un fenómeno conocido como party patronage. Al depender del partido político el acceso a cargos públicos, el acceso a posiciones electas será más restringido para los miembros de las organizaciones juveniles, teniendo este incentivo un menor efecto. Estas solo disponen de posiciones en los órganos ejecutivos de su estructura organizativa. El trabajo de Bruter y Harrison (2009) señala que los jóvenes que están motivados por este incentivo, además de ser el grupo más numeroso, son más activos.

Los incentivos de proceso son los beneficios derivados del propio acto de participación en las diferentes actividades (Seyd y Whiteley, 1992: 64). Puede ser la oportunidad de conocer gente interesante en otros escenarios con la que compartir ideas políticas, disfrutar con la actividades que rodean la política, por ejemplo en un campańa electoral, en el sentido de disfrutar de la vida política de primera mano, o incluso estar informado sobre temas políticos. La presencia de este incentivo es similar tanto para los miembros del partido político como de la organización juvenil. Rainsford, (2018) encuentra que este tipo de incentivos es una de las principales motivaciones para el activismo entre los miembros de las organizaciones juveniles de los partidos políticos británicos. 
Se espera que la presencia de este incentivo entre los jóvenes esté relacionada con mayores niveles de activismo.

Los incentivos ideológicos son el tercer tipo de incentivo que estimula el proceso de la motivación y puede ubicarse bajo los presupuestos de la ley de la disparidad ideológica (Whiteley et al., 1994b: 85: Whiteley y Sedy, 1996: 219), también conocida como la ley de May (May, 1973). Una razón argumentada para unirse a un partido político ha sido la ideología (Smith, 1970: 127; Young y Cross, 2002: 549; van Haute, 2015: 42). Los incentivos ideológicos, por tanto, se establecen bajo presupuestos de cambiar la sociedad, en defensa de un específico issue o la defensa de ciertos valores. Un considerable número de investigadores retoma este tipo de incentivos para tratar de explicar el activismo en términos de creencias políticas o de policy related beliefs (Young y Cross, 2002). Tal y como exponen Whiteley y Seyd (2002: 53) la relación no ha sido bien fundada teóricamente, si bien la implicación se relaciona con los motivos de proceso, de tal modo que el radicalismo ideológico debería motivar a las personas para ser activas, ya que les permite interactuar con personas de ideas afines y expresar sus creencias políticas que están profundamente arraigadas. Asimilan esta relación a la presente en los miembros activos de la iglesia, que les permite expresar sus creencias y formar parte de la congregación (Seyd and Witheley 1992: 100; Whiteley y Seyd, 2002: 53). A nivel empírico, el impacto de la ideología sobre el activismo es residual tanto en los militantes británicos como entre los irlandeses (Gallagher et al., 2002: 106). No se espera una especial relación entre ambas variables en los miembros de las organizaciones juveniles.

\section{MODELO DE INCENTIVOS GENERALES}

La idea central es que los individuos están motivados para participar y tienen valores cívicos positivos por varios tipos de incentivos (Seyd y Whiteley, 1992: 63; Pattie et al., 2004: 15). El modelo se configura como un híbrido al incluir las variables señaladas en el modelo de elección racional, en sus versiones simple y ampliada, e incorporar otros motivos para el activismo ajenos a él. Al análisis coste-beneficio añade los incentivos selectivos y otras motivaciones que se encuentran fuera del análisis racional: las normas sociales, los motivos altruistas, la eficacia política grupal y el factor afectivo (Seyd y Whiteley, 1992).

Las normas sociales suponen el efecto de las actitudes hacia la participación de otras personas, normalmente gente próxima, que influyen sobre las propias actitudes individuales. Las normas sociales se entienden como la aprobación o desaprobación de la conducta que refuerza o motiva a la gente para participar, es decir, está determinada por el deseo de ganar el respeto o la 
aprobación de otras personas (Cross y Young, 2008). En el caso de los miembros de las organizaciones juveniles la influencia esperada de las normas sociales será alta. Debido a los efectos del ciclo de vida, los jóvenes tienen más probabilidades de ser sensibles a las normas y factores sociales que sus mayores. El activismo probablemente será más alto en aquellos jóvenes en los que su contexto apoye la participación en partidos políticos.

En cuanto a los motivos altruistas, los mismos están relacionados con el principio de que la participación es una cuestión de obligación cívica por parte de todos los ciudadanos para sostener la democracia (Whiteley et al., 1994a: 116). Los miembros participan bajo la premisa de que si todos tomamos el papel de free-rider, los objetivos colectivos no se conseguirán, pero a pesar de eso deciden por un sentido de lealtad o afección ser activos en la formación política. Estos motivos recaen sobre una unión emocional y a menudo son expresados como objetivos idealistas o imperativos morales como "hacer del mundo un lugar mejor» o "eso es lo que hay que hacer» (Seyd y Whiteley, 1992: 107; Whiteley at al., 1994a: 116).

La eficacia política grupal, también denominada eficacia política externa, mide el sentido en el cual el individuo está motivado para estar activo si él cree que forma parte de una organización política que es capaz de conseguir sus objetivos (Whiteley et al., 1994a). En el caso de los miembros de la organización juvenil, al ser esta una organización separada, pero con un funcionamiento propio, la eficacia política grupal no se verá más difuminada. Se espera que una alta perfección de la eficacia política grupal esté relacionada con altos niveles de activismo.

El factor afectivo, también denominado factor expresivo, es el grado en el que la participación está justificada por el apoyo normativo o expresivo a la formación política. Es definido como efecto de la unión afectiva individual hacia el sistema político, y que influye en sus valores y puede motivar la participación. Radica en la identificación con la formación política. Muestra mayores niveles entre los miembros de los partidos que entre los simpatizantes (Poletti et al., 2019). Se espera que una alta identificación con la organización juvenil esté relacionada con un mayor activismo.

\section{DATOS}

Para evaluar la pertinencia del modelo de incentivos generales se utilizan los datos de una encuesta realizada en el marco de una investigación a los miembros de las organizaciones juveniles de los partidos políticos españoles. El trabajo de campo se realizó entre los meses de abril y noviembre de 2016 mediante un cuestionario online en formato autoadministrado, y distribuido 
vía correo electrónico entre los miembros de las organizaciones políticas juveniles ${ }^{3}$. El enlace al cuestionario, alojado en Limesurvey, fue enviado por email gracias a la colaboración de la estructura interna de las organizaciones juveniles. En este trabajo se utilizan los cuestionarios de Juventudes Socialistas de España (JSE), organización vinculada al Partido Socialista Obrero Español —al igual que Joventut Socialista de Catalunya (JSC) al Partit dels Socialistes de Catalunya-, que se enviaron vía email con el enlace a la lista de distribución que es usada como canal de comunicación con sus miembros. Entre estas dos formaciones, después de un proceso de depuración se obtuvieron un total de 900 cuestionarios válidos. El mismo proceso aconteció con los jóvenes vinculados con Izquierda Unida (IU), con un total de 420 cuestionarios $^{4}$. En el caso de Nuevas Generaciones (NNGG), organización vinculada al Partido Popular, el email se envió desde la sede nacional de la formación política a una selección aleatoria de 1000 afiliados, y tras la depuración se obtuvieron un total de 499 cuestionarios útiles. En el conjunto de las tres formaciones, se obtuvo una muestra de 1809 personas $^{5}$. La metodología empleada para el tratamiento de los datos ha implicado la realización de diferentes análisis estadísticos, algunos de ellos sobre el conjunto de la muestra y, en otros casos, sobre las diferentes submuestras o subgrupos, a fin de obtener un mayor volumen de evidencias.

\section{EL ACTIVISMO DE LOS MIEMBROS DE LOS PARTIDOS POLÍTICOS: EL TIEMPO DEDICADO A ACTIVIDADES PARTIDISTAS}

El activismo, como variable dependiente en los diversos modelos teóricos comentados con anterioridad, ha sido trabajado a partir del tiempo dedicado a la realización de actividades políticas. Para la medición de este tiempo dedicado a las diferentes actividades propias de los miembros de los partidos políticos se han utilizado diferentes medidas. Una medida estándar del activismo

3 El formato elegido se seleccionó por posibilitar un mayor anonimato, confidencialidad y adecuación con la normativa de protección de datos, y adecuarse a los requisitos de las propias organizaciones juveniles.

4 Bajo el paraguas de IU operan diferentes partidos políticos que forman la coalición. En este grupo se han incluido las diferentes organizaciones juveniles vinculadas a ellos: IU Jóvenes; la Unión de Juventudes Comunistas de España (UJCE), vinculada al Partido Comunista de España (PCE), y Jóves de Iniciativa per Catalunya-Vers.

5 En el supuesto de haber realizado un muestro aleatorio simple, el error muestral para un nivel de confianza del $95 \%, y \mathrm{p}=\mathrm{q}=0,5$, es de 3,1 para la formación socialista, 4,3 para NNGG, 5,5 para las organizaciones vinculadas con IU y 2,2 para el conjunto de la muestra. 
y ampliamente aceptada por un gran uso se interesa por el número de horas dedicadas a las actividades partidistas en un mes normal (Seyd y Whiteley, 1992, 1994; Whiteley et al., 1994a, 1994b; Cross y Young, 2004; Gallagher y Marsh, 2004; Pedersen et al., 2004).

Los trabajos empíricos sobre los miembros de los partidos políticos señalan que una gran cantidad de ellos no dedican parte de su tiempo a las actividades del partido de manera habitual y solo un grupo reducido pueden considerarse activistas. Muchos de ellos permanecen inactivos desde su unión y no tienen intención de ser activos (Gallagher y Marsh, 2004; Pedersen et al., 2004; Seyd y Whiteley, 2004). Por ejemplo, en el Reino Unido, hasta un $50 \%$ de los laboristas y un $75 \%$ de los conservadores señalan que durante un mes corriente no realizan ningún tipo de actividad partidista, aunque sí la han realizado durante los últimos cinco años (Whiteley y Seyd, 2002: 95-97); en Flandes, el 55,6\% de los miembros del Partido Liberal se declaran pasivos (Van Haute, 2011: 180). Un análisis diacrónico (1991-2000) de los miembros de los partidos políticos noruegos señala que más del $50 \%$ de ellos declaraban no haber tomado parte en las actividades propias de la formación en el último año, y cerca del $20 \%$ no tenía la intención de participar en ellas (Heidar y Saglie, 2003: 770), mientras que el 56\% era completamente pasivo y solo el $31 \%$ era semiactivo con un activismo menor de cinco horas al mes (Pedersen et al., 2004: 375). En Irlanda, entre los miembros del Fine Gael el $55 \%$ no dedicaba parte de su tiempo a la realización de actividades partidistas (Gallagher y Marsh, 2004: 413). En el Reino Unido, los partidos Conservador y Laborista desde la década de los noventa han ido perdiendo energía (Whiteley y Seyd, 2002: 95), y este menor nivel de activismo ha sido percibido, incluso, por los propios miembros de las formaciones políticas (Gallager y Marsh, 2004: 413).

En este punto nos interesa saber si estos niveles de participación dentro de los partidos políticos europeos son extrapolables a los partidos políticos españoles y, más concretamente, a las organizaciones juveniles vinculadas a ellos. En este trabajo se ha optado por usar el tiempo semanal dedicado a las diferentes actividades derivadas de la afiliación partidista. En la tabla 1 se muestran los porcentajes para las tres fuerzas políticas juveniles contempladas en este trabajo. Los datos señalan que el porcentaje de miembros pasivos es muy escaso y que más del $50 \%$ de los jóvenes dedica de una a diez horas a la semana a actividades políticas o relacionadas con la actividad política. Los valores muestran niveles de actividad muy superiores a los encontrados en la

6 Preguntados sobre su nivel de activismo en la actualidad comparado con los cuatro años anteriores, el $20 \%$ era más activo y el $32 \%$ menos activo. 
literatura sobre el activismo en los partidos políticos (véase, por ejemplo, Seyd y Whiteley, 1992; Whiteley et al., 1994a; Gallagher y Marsh, 2004; Cross y Young, 2008; Scarrow, 2015; van Haute y Gauja, 2015).

Tabla 1. Tiempo dedicado a las actividades politicas en una semana normal (\%)

\begin{tabular}{lccc}
\hline & JSE / JSC & NNGG & Juventudes IU \\
\hline Nada & 6 & 12,4 & 1,5 \\
\hline Menos de 1 hora & 14 & 10,6 & 5,6 \\
\hline De 1 a 2:30 horas & 21,9 & 20,2 & 11,5 \\
\hline De 2:30 a 5 horas & 17,4 & 18 & 21,5 \\
\hline De 5 a 10 horas & 13,3 & 14,4 & 20,2 \\
\hline De 10 de 20 horas & 9,1 & 8,4 & 19,3 \\
\hline De 20 a 40 horas & 5,7 & 5,4 & 7,8 \\
\hline Más de 40 horas & 6,8 & 3 & 7,6 \\
\hline No sabe /No contesta & 5,8 & 7,4 & 5,1 \\
\hline N & 900 & 499 & 410 \\
\hline
\end{tabular}

Fuente: elaboración propia.

A pesar de no diferenciar entre los diferentes tipos de actividades realizadas, la respuesta a esta cuestión permite realizar una segmentación de sus miembros en función del tiempo dedicado a la formación política en tres grupos: a) miembros pasivos, que serían aquellos que no dedican parte de su tiempo a la realización de actividades relacionadas con la formación política, y que son en torno al $6 \%$ de la muestra; b) un segundo grupo de miembros semipasivos, con una dedicación de menos de cinco horas, lo que supone casi la mitad de la muestra, y c) un tercer grupo que realiza actividades durante más de cinco horas a la semana, con valores cercanos al $40 \%$.

Entre las diversas formaciones políticas encontramos diferencias. Los más activos son los afiliados a las organizaciones vinculadas con IU, donde el $55 \%$ de sus miembros dedica más de cinco horas en una semana a las actividades políticas. Entre socialistas y populares, este porcentaje desciende a algo más del $30 \%$ en cada organización. El porcentaje de jóvenes pasivos varía en función de las formaciones, y es entre los militantes de NN GG donde encontramos una cifra muy superior a la presente entre los miembros de JSE y 
formaciones vinculadas con IU. Estos datos constatan lo indicado por Bruter y Harrison (2009: 67) acerca de que los miembros de pequeños partidos se declaran más activos y que los jóvenes miembros de partidos socialistas son más activos que los conservadores. En cualquier caso, los datos indican un alto nivel de activismo entre los miembros de las tres organizaciones juveniles de los partidos políticos, situación esta que ha sido señalada en otras latitudes (Cross y Young, 2008; Bargel y Dechezelles, 2009; Bruter y Harrison, 2009)7.

\section{LAS VARIABLES INDEPENDIENTES DE LOS MODELOS EXPLICATIVOS DEL ACTIVISMO}

En los siguientes subepígrafes se ofrece la operacionalización de las variables que componen los diferentes modelos teóricos objeto de evaluación. Se expone la ecuación que fundamenta cada uno de ellos, sus respectivas variables, la construcción y medición. Cuatro variables de carácter sociodemográfico se han introducido para controlar los efectos sobre la variable dependiente: género (GE), edad (ED), estatus social (ES) y educación (NE). Los trabajos sobre los miembros de los partidos políticos han señalado que estas variables están relacionadas con la participación en su seno (Cross y Young, 2008a; Baras et al., 2010; Scarrow y Gezgor, 2010; Alarcón, 2017; Bale et al., 2019). Estas variables se alejan del modelo de elección de racional y del modelo de incentivos generales, pero han ayudado a explicar las diferencias en la participación en un gran número de investigaciones bajo una explicación de la participación basada en los recursos (Verba et al., 1995). La ecuación de estas variables de control queda establecida en los siguientes términos:

(1) Activismo $=a+\beta 1 * G E+\beta 2 * E D+\beta 3 * N E+\beta 4 * E S+\mu$

El género ha sido señalado como una de las principales diferencias en la composición de los partidos políticos con respecto a la sociedad en general. Los partidos políticos están mayoritariamente compuestos por hombres. En cuanto a la relación de esta variable con el activismo, el trabajo de Cross y

7 El trabajo de Cross y Young (2008: 260) sobre el activismo de los jóvenes militantes canadienses señala que el $20 \%$ de los miembros son inactivos, el $50 \%$ de ellos dedica menos de cinco horas y el $30 \%$ más de cinco horas al mes en actividades propias del partido político. Entre los Jeunes Populaires franceses, el $49 \%$ declara consagrar hasta dos horas, el $28 \%$ una media de cinco horas y el $23 \%$ más de diecinueve horas (Bargel y Dechezelles 2009: 57). 
Young en Canadá (2008) señala que ellos presentan niveles de activismo más altos, mientras que entre los miembros de los partidos británicos, Seyd y Whiteley (1992) ven una relación débil entre género y activismo. La variable género mide el sexo de la persona entrevistada.

En cuanto a la edad, algunos trabajos apuntan a que los jóvenes (26-35 años) son el grupo más activo en relación con el conjunto de militantes (Whiteley et al., 2006: 95), y dentro de las formaciones juveniles, los más jóvenes (aquellos menores de 25 años) son más activos que los mayores de 26 (Cross y Young, 2008). La variable utilizada mide la edad en años cumplidos.

El nivel educativo y el estatus social se asocian a un mayor interés y comprensión de la política (Pattie et al., 2004). Los trabajos señalan que aquellos miembros más activos tienen un estatus social más alto que los miembros pasivos. Para esta variable se utiliza un proxi, ya que en adolescentes y jóvenes es complicado obtener una medida del estatus socioeconómico familiar. En este caso el número de libros en casa ha sido señalado como un indicador fiable del estatus socioeconómico (Hooghe y Dassonnneville, 2013). Para el nivel educativo se pregunta por el último completado a la fecha de la entrevista. Los descriptivos de estas cuatro variables y de las que se establecen en los próximos subepígrafes están en el anexo 1.

\section{EL MODELO DE ELECCIÓN RACIONAL BÁSICO}

En la ecuación de la versión simple del modelo de elección racional, el activismo es el resultado de la percepción de la eficacia política personal (EPI) por el beneficio colectivo (BC) y por el coste de participar (CO). A estas variables también se unen las cuatro variables de control establecidas en el apartado anterior: género (GE), edad (ED), nivel educativo (NE) y estatus social (ES).

(2) Activismo $=a+\beta 1 * G E+\beta 2 * E D+\beta 3 * N E+\beta 4 * E S+\beta 5 * E P I+\beta 6 * B C+\beta 7 *$ $\mathrm{CO}+\mu$

Eficacia política individual (EPI)

El indicador utilizado es el resultado del sumatorio de seis ítems medidos en una escala tipo Likert que oscila entre 1 («muy de acuerdo») a 5 («muy en desacuerdo»): «Generalmente, la política es tan complicada que la gente como yo no puede entender lo que pasa»; «Estoy mejor informado/a sobre política que la mayoría de la gente» (puntúa al revés); «La gente como yo puede influir realmente en política si está dispuesta participar» (puntúa al revés); "Nombre organización juvenil tendría más éxito si personas como yo tuviéramos más influencia en la organización» (puntúa al revés); «Soy 
capaz de entender fácilmente la mayoría de las cuestiones políticas» (puntúa al revés); "Cuando se discute sobre temas políticos siempre tengo algo que decir» (puntúa al revés).

\section{Beneficio colectivo (BC)}

Los beneficios colectivos miden la percepción sobre si el sistema en su conjunto funciona bien y puede proporcionar beneficios para el individuo. La variable mide el nivel de satisfacción con el desempeño del sistema político, que no es otra cosa que la satisfacción con la democracia (Pattie et al., 2004). La variable recoge esta repuesta en una escala que oscila entre 0 («muy insatisfecho») y 10 («muy satisfecho con el funcionamiento de la democracia»).

Coste (CO)

La variable es el sumatorio de tres afirmaciones medidas en un escala tipo Likert (1-5), (1 es «muy de acuerdo" y 5 "muy en desacuerdo»): "Asistir a reuniones políticas después de un duro día de trabajo puede ser agotador» (puntúa al revés); «A veces trabajar para la organización juvenil puede resultar aburrido» (puntúa al revés), y «Lo normal es que la actividad política te quite tiempo para dedicarlo a la familia» (puntúa al revés).

\section{EL MODELO DE ELECCIÓN RACIONAL AMPLIADO}

La primera versión del modelo de elección racial es reformulada en una versión extendida bajo los presupuestos de Olson, incorporando a ella los incentivos selectivos de resultado, los incentivos selectivos de proceso y los incentivos ideológicos a la ecuación del activismo (2). La formulación se establece en los siguientes términos:

(3) Activismo $=a+\beta 1 * G E+\beta 2 * E D+\beta 3 * N E+\beta 4 * E S+\beta 5 * E P I+\beta 6 * B C+\beta 7 *$ $C O+\beta 8 * I R+\beta 9 * I P+\beta 10 * I I+\beta 11 *+\mu$

Incentivos de resultado (IR)

Están medidos como los beneficios individuales derivados de involucrase en las actividades del partido político y que están relacionados con la consecución de posiciones políticas o cierto estatus político. El indicador recoge el sumatorio de dos ítems: "Alguien como yo podría hacer un buen trabajo como representante público», y «El partido tendría más éxito si más gente 
como yo fuéramos elegidos para el Parlamento». Están medidos un escala tipo Likert (1-5, donde 1 es «muy de acuerdo» y 5 «muy en desacuerdo»).

Incentivos de proceso (IP)

Este tipo de beneficio selectivo es derivado de la propia participación en el seno de la organización política. El indicador recoge la repuesta a los siguientes tres ítems, medidos en una escala tipo Likert 1-5, donde 1 es «muy de acuerdo» y 5 «muy en desacuerdo»: «La única forma de estar realmente informado sobre temas políticos es a través del partido» (puntúa al revés); «El partido es una buena manera de conocer gente interesante» (puntúa al revés), $\mathrm{y}$ "Participar en las actividades que rodean unas elecciones es algo divertido" (puntúa al revés).

Incentivos ideológicos (II)

La medida, según los trabajos precedentes de los militantes británicos y los presupuestos de May (1973), se establece entre la autoubicación ideológica del miembro de la formación política juvenil y la ubicación del resto de miembros. En concreto, no es otra cosa que la posición percibida en la escala ideológica en función de la ubicación en ella del conjunto de miembros de la formación política. La variable recoge las posiciones más extremas (aquellos que se posicionan más hacia los extremos) en función de la ubicación ideológica media de los miembros de la formación juvenil.

\section{EL MODELO DE INCENTIVOS GENERALES}

El modelo de incentivos generales recupera el modelo de elección racional, al que añade otros factores. La formulación queda establecida con la incorporación de los modelos anteriores, las cuatro variables sociodemográficas, la eficacia política interna (EPI), el beneficio colectivo (BC), el coste de participación (CO), los incentivos de resultado (IR), los incentivos de proceso (IP) y los incentivos ideológicos (II). A estos se añaden los motivos altruistas (MA), las normas sociales (NS), la eficacia política grupal (EPG) y un factor afectivo (FA).

(4) Activismo $=a+\beta 1 * G E+\beta 2 * E D+\beta 3 * N E+\beta 4 * E S+\beta 5 * E P I+\beta 6 * B C+\beta 7 *$ $C O+\beta 8 * I O+\beta 9 * I R+\beta 10 * I I+\beta 11 * N S+\beta 12 * M A+\beta 13 * E P G+\beta 14 * F A+\mu$ 


\section{Normas sociales (NS)}

El indicador de la norma social es la sumatorio de los siguientes ítems ${ }^{8}$, medidos en una escala 1 («muy de acuerdo») a 5 («muy en desacuerdo»): «En general los miembros de organizaciones políticas juveniles son personas respectadas en la sociedad»; «El trabajo realizado por los militantes de base a menudo no está reconocido» (puntúa al revés); «La única forma de cambiar algo es participando activamente», y "Los miembros de organizaciones políticas juveniles son personas extremistas» (puntúa al revés).

\section{Motivos altruistas (MA)}

El altruismo en la formación política se conceptualiza como el éxito en el trabajo derivado del esfuerzo común. El indicador es el sumatorio de dos ítems: "Para que los nombre miembros de la formación tengamos un éxito razonable todos los miembros deben contribuir tanto como puedan» y «Si un ciudadano no está satisfecho con las políticas del Gobierno, tiene el deber de hacer algo al respecto", ambos en una escala tipo Likert de 1 («muy de acuerdo») a 5 («muy en desacuerdo»), y ambos ítems puntúan al revés.

\section{Eficacia política grupal (EPG)}

$\mathrm{El}$ indicador es el sumatorio de tres afirmaciones que fueron medidas en una escala 1 («muy de acuerdo») a 5 («muy en desacuerdo»): "Cuando los miembros de mi partido trabajan juntos pueden realmente cambiar el país»; "Los líderes del partido generalmente no escuchan a los militantes jóvenes» (puntúa al revés), y «Los nombre formación han influido en el desarrollo de mi municipio».

\section{Factor afectivo (FA)}

Se interpreta como la fuerza del compromiso o la identificación hacia al partido. El indicador es la respuesta a la pregunta ¿Cómo de identificado/a te sientes con nombre organización juvenil?, que oscila entre 1 («muy identificado» y 4 («nada identificado») (al revés).

8 La pregunta está formulada en los siguientes términos: «Piensa en aquellas personas cuya opinión es importante para ti, como por ejemplo tu pareja, tus amigos/as, etc. ¿En qué grado se mostrarían de acuerdo con cada una de las siguientes afirmaciones?». 


\section{LOS INCENTIVOS EN LOS MIEMBROS DE LAS ORGANIZACIONES JUVENILES: SIMILITUDES Y DIFERENCIAS}

A continuación se presentan los descriptivos para las tres fuerzas políticas de los diferentes incentivos y factores identificados como determinantes del activismo. En la tabla 2, las respuestas de los ítems que dan cuerpo al modelo de elección racional en su versión simple y extendida, y en la tabla 3 se recogen los factores asociados al modelo de incentivos generales.

En general, en las tres fuerzas políticas la percepción de la eficacia política individual es alta, a tenor de los porcentajes agregados de las respuestas «bastante» y «muy de acuerdo» en cada uno de los ítems. La excepción sería el ítem que hace referencia al éxito de la organización si más personas como «el/ ella» tuvieran mayor influencia, donde los valores en las formaciones de izquierda no llegan al $50 \%$, entre las que los miembros de las organizaciones vinculadas a IU es inferior al $25 \%$. En cambio, en esta formación la percepción de la competencia individual en términos de comprensión y de información es más elevada que entre los miembros de JSE y NN GG.

Tabla 2. Items de eficacia politica personal, costes e incentivos selectivos (\% muy de acuerdo y de acuerdo) y beneficio colectivo

\begin{tabular}{|c|c|c|c|}
\hline & JSE/JSC & NNGG & $\begin{array}{l}\text { Juventudes } \\
\text { IU }\end{array}$ \\
\hline \multicolumn{4}{|l|}{ Eficacia política personal } \\
\hline $\begin{array}{l}\text { Generalmente, la política es tan complicada que } \\
\text { la gente como yo no puede entender lo que pasa. }\end{array}$ & 14,9 & 12,2 & 9,3 \\
\hline $\begin{array}{l}\text { Estoy mejor informado/a sobre política que la } \\
\text { mayoría de la gente. }\end{array}$ & 65,8 & 66,6 & 74,1 \\
\hline $\begin{array}{l}\text { La gente como yo puede influir realmente en } \\
\text { política si está dispuesta participar. }\end{array}$ & 78 & 79,8 & 83,5 \\
\hline $\begin{array}{l}\text { «Nombre organización juvenil» tendría más éxito } \\
\text { si personas como yo tuviéramos más influencia } \\
\text { en la organización. }\end{array}$ & 45,4 & 55,3 & 24,2 \\
\hline $\begin{array}{l}\text { Soy capaz de entender fácilmente la mayoría de } \\
\text { las cuestiones políticas. }\end{array}$ & 81,9 & 83,3 & 79,5 \\
\hline $\begin{array}{l}\text { Cuando se discute sobre temas políticos siempre } \\
\text { tengo algo que decir. }\end{array}$ & 76,6 & 75,6 & 73,9 \\
\hline
\end{tabular}


.../..

JSE/JSC NNGG Juventudes

IU

\section{Beneficio colectivo}

\begin{tabular}{lccc}
\hline Media & 4,85 & 6,12 & 1,61 \\
\hline Desviación típica & 2,339 & 2,396 & 1,833 \\
\hline
\end{tabular}

\section{Coste}

Asistir a reuniones políticas después de un duro día de trabajo puede ser agotador.

$54,2 \quad 50,9 \quad 74,9$

A veces trabajar para la organización juvenil puede resultar aburrido.

$17,6 \quad 21,4 \quad 22,6$

Lo normal es que la actividad política te quite tiempo para dedicarlo a la familia.

$55,9 \quad 48,7 \quad 62,4$

\section{Incentivos de resultado}

Alguien como yo podría hacer un buen trabajo como representante público.

$68,2 \quad 72,8 \quad 44,3$

El partido tendría más éxito si más gente como yo fuéramos elegidos para el Parlamento.

$47,6 \quad 49,3 \quad 20,5$

\section{Incentivos de proceso}

La única forma de estar realmente informado sobre temas políticos es a través de partido.

El partido es una buena manera de conocer gente interesante.

$25 \quad 28,4 \quad 17,5$

Participar en las actividades que rodean unas elecciones es algo divertido.

\begin{tabular}{lll}
78,4 & 74,4 & 77,8 \\
\hline 46,6 & 73,9 & 42,6
\end{tabular}

\section{Indicadores ideológicos}

Porcentaje más extremo

$19,3 \quad 33,7 \quad 30,7$

Fuente: elaboración propia.

En cuanto al beneficio colectivo, este es más alto en los jóvenes miembros de NNGG. Este hecho puede deberse a su posición de partido en el Gobierno en el momento de realizarse el trabajo de campo. En cambio, en las formaciones vinculadas a la izquierda del centro, socialistas y comunistas, el beneficio colectivo es más bajo. Podría deberse a su posición de oposición al Gobierno o a un perfil más crítico entre sus miembros, acentuado sobre 
todo entre las formaciones vinculadas a IU sobre la calidad de la democracia.

En general, a la luz de los datos, los jóvenes militantes consideran que el trabajo en la organización juvenil no es algo aburrido, ya que solo uno de cada cinco lo ve como algo tedioso. Al mismo tiempo, consideran en mayor medida —uno de cada dos - que las actividades políticas quitan tiempo a la familia y que las reuniones para tratar temas políticos tras una jornada laboral pueden resultar pesadas. Estos costes se perciben en un porcentaje mayor entre los miembros de las formaciones de izquierda, sobre todo en las juventudes de IU.

Los incentivos selectivos relacionados con los resultados del activismo están más presentes entre los miembros de JSE y NN GG. Entre los miembros de esta última formación ambos ítems presentan valores más altos, sobre todo en la autopercepción de la competencia personal, donde tres de cada cuatro creen que podrían hacer un buen trabajo como representante público.

De media, los incentivos selectivos ligados al proceso presentan valores muy similares en las tres formaciones. Consideran los tres subgrupos en gran medida que la formación política ayuda a conocer gente interesante (tres de cada cuatro están muy de acuerdo o de acuerdo con esta afirmación). El disfrute con la participación en las campañas electorales es mayor en los afiliados a NNGG que en las otras formaciones (tres de cada cuatro miembros). El tercer ítem que controla el acceso a la información vía partido como incentivo para la militancia, presenta valores bajos en las tres formaciones, lo que señala que la formación política no es percibida como un elemento importante para estar informado sobre temas políticos.

En relación con los incentivos ideológicos, solo uno de cada cuatro jóvenes presenta valores más extremos en la escala de identificación ideológica. El porcentaje es superior entre los militantes de NNGG (33,7\%), seguidos por los jóvenes de IU (30,7\%).

En la tabla 3 se recogen los descriptivos del factor afectivo, las normas sociales, los motivos altruistas y la eficacia política grupal. Las normas sociales presentan la misma orientación entre las tres formaciones políticas, con pequeñas diferencias. Tres de cada cuatro jóvenes perciben que los jóvenes activistas no son respetados por la sociedad. En las otras tres afirmaciones hay mayor variabilidad en los porcentajes de respuesta acumulada. Los jóvenes socialistas son los que perciben en mayor grado que el trabajo que realizan no está reconocido, con casi un $86 \%$. Este porcentaje baja unos diez puntos en las formaciones vinculadas a IU. En cambio, los miembros de NNGG perciben en mayor medida el respaldo social en cuanto que la única forma de cambiar algo es participando (el porcentaje asciende casi al 90\%.) La diferencia más apreciable se produce en la percepción del extremismo de los jóvenes militantes, que en el caso de los miembros vinculados a IU llega casi 
al $25 \%$, mientras que tiene valores menores al $12 \%$ entre las formaciones vinculadas al PSOE y PP.

Los motivos altruistas, es decir, al éxito derivado del trabajo común, son percibidos por los jóvenes miembros de los partidos políticos con valores altos,

Tabla 3. Items de normas sociales, motivos altruistas y eficacia politica grupal (\% de muy de acuerdo y de acuerdo) y de factor afectivo (\%)

\begin{tabular}{|c|c|c|c|}
\hline & JSE/JSC & NNGG & $\begin{array}{c}\text { Juventudes } \\
\text { IU }\end{array}$ \\
\hline \multicolumn{4}{|l|}{ Normas sociales } \\
\hline $\begin{array}{l}\text { El general los miembros de organizaciones } \\
\text { políticas juveniles son personas respetadas en la } \\
\text { sociedad. }\end{array}$ & 24,9 & 26,7 & 22,9 \\
\hline $\begin{array}{l}\text { El trabajo realizado por los militantes de base a } \\
\text { menudo no está reconocido. }\end{array}$ & 85,8 & 80,6 & 75,6 \\
\hline $\begin{array}{l}\text { La única forma de cambiar algo es participando } \\
\text { activamente. }\end{array}$ & 82,9 & 89,2 & 76,3 \\
\hline $\begin{array}{l}\text { Los miembros de organizaciones juveniles son } \\
\text { personas extremistas. }\end{array}$ & 11,2 & 12,2 & 24,1 \\
\hline \multicolumn{4}{|l|}{ Motivos altruistas } \\
\hline $\begin{array}{l}\text { Para que los «nombre partido» tengamos un } \\
\text { éxito razonable todos los miembros deben } \\
\text { contribuir tanto como puedan. }\end{array}$ & 76,6 & 72,7 & 83,1 \\
\hline $\begin{array}{l}\text { Si un ciudadano no está satisfecho con las } \\
\text { políticas del Gobierno, tiene el deber de hacer } \\
\text { algo al respecto. }\end{array}$ & 75,9 & 63,5 & 85,1 \\
\hline \multicolumn{4}{|l|}{ Eficacia política grupal } \\
\hline $\begin{array}{l}\text { Cuando los miembros de mi partido trabajan } \\
\text { juntos pueden realmente cambiar el país. }\end{array}$ & 82,1 & 78,4 & 77,8 \\
\hline $\begin{array}{l}\text { Los líderes del partido generalmente no escuchan } \\
\text { a militantes jóvenes. }\end{array}$ & 69,5 & 46,6 & 32 \\
\hline $\begin{array}{l}\text { Mi «nombre partido» ha influido en el desarrollo } \\
\text { de mi municipio. }\end{array}$ & 85,8 & 73,7 & 49,7 \\
\hline \multicolumn{4}{|l|}{ Factor afectivo } \\
\hline «Muy identificado» $\mathrm{y}$ «bastante identificado» & 86,8 & 82,5 & 94,4 \\
\hline
\end{tabular}

Fuente: elaboración propia. 
superiores de media al $65 \%$ en respuesta acumulada de «muy de acuerdo» y «de acuerdo». Esto supone que tres de cada cuatro jóvenes ven su participación como fundamental para alcanzar los objetivos de la formación política. Hay que apuntar en cuanto a la participación ante la insatisfacción por las políticas gubernamentales, que los miembros de las dos formaciones de izquierda muestran mayores porcentajes («de acuerdo» $\mathrm{y}$ «muy de acuerdo» en la actuación) que los jóvenes de NN GG.

Los datos de la eficacia política grupal indican que el poder transformador de la formación política en la sociedad es visto con altos porcentajes entre los miembros de las tres formaciones juveniles; este crédito desciende en la percepción sobre la influencia en su municipio de su partido político, sobre todo entre las formaciones juveniles de IU. En cuanto a si la opinión de los jóvenes es escuchada por los líderes del partido, destaca el alto porcentaje de jóvenes socialistas que consideran que ellos no son escuchados por sus dirigentes (el porcentaje de "muy de acuerdo» y «de acuerdo» es del $70 \%$ ). En cambio, el porcentaje desciende a uno de cada tres entre los miembros de las formaciones vinculadas con IU.

La última de las variables de la tabla 3 muestra los datos del factor afectivo. En las tres formaciones el porcentaje de «bastante identificado» $\mathrm{y}$ «muy identificado» con la organización política juvenil es superior al $80 \%$, y alcanza en los miembros de las formaciones vinculadas con IU el $95 \%$.

\section{ANÁLISIS Y DISCUSIÓN DE LOS MODELOS EXPLICATIVOS DEL ACTIVISMO}

En la tabla 4 se presenta el análisis de regresión lineal realizado con los diferentes modelos teóricos explicativos para el total de la muestra, controlando por fuerza política (media y desviación típica en anexo). Para ello, se incluyen dos variables ficticias (dummy) que representan a los tres grupos de militantes analizados. De esta forma, se controlan los efectos fijos inherentes a las formaciones políticas y se pueden observar mejor los efectos que son comunes al conjunto de la muestra ${ }^{9}$. No obstante, para capturar mejor las particularidades dentro cada formación, como se acaba de señalar, se replican los modelos para cada uno de ellas en la tabla 5, controlando por doble militancia —en aquellas formaciones donde es posible este supuesto-.

9 Los diferentes modelos toman como categoría de referencia a la formación socialista. De las tres organizaciones, a esta se le puede atribuir la centralidad ideológica, en cuanto que está más a la derecha que las organizaciones vinculadas con IU y más a la izquierda que NNGG. 
Tabla 4. Regresión lineal para el total de la muestra de militantes y para las diferentes formaciones politicas

\begin{tabular}{|c|c|c|c|c|}
\hline & 1 & 2 & 3 & 4 \\
\hline Género† & $\begin{array}{c}-0,411^{* * *} \\
(0,179)\end{array}$ & $\begin{array}{c}-0,349^{* * *} \\
(0,140)\end{array}$ & $\begin{array}{c}-0,334^{* *} \\
(0,109)\end{array}$ & $\begin{array}{c}-0,319^{* *} \\
(0,109)\end{array}$ \\
\hline Edad & $\begin{array}{c}1,225^{* * *} \\
(0,327)\end{array}$ & $\begin{array}{c}1,224^{* * *} \\
(0,353)\end{array}$ & $\begin{array}{l}1,143^{* *} \\
(0,361)\end{array}$ & $\begin{array}{l}1,006^{* *} \\
(0,361)\end{array}$ \\
\hline Estatus & $\begin{array}{c}0,561^{* * *} \\
(0,161)\end{array}$ & $\begin{array}{c}0,344^{*} \\
(0,176)\end{array}$ & $\begin{array}{l}0,350^{*} \\
(0,181)\end{array}$ & $\begin{array}{c}0,395^{*} \\
(0,180)\end{array}$ \\
\hline Educación & $\begin{array}{l}-0,217 \\
(0,268)\end{array}$ & $\begin{array}{c}0,138 \\
(0,292)\end{array}$ & $\begin{array}{c}0,254 \\
(0,304)\end{array}$ & $\begin{array}{c}0,328 \\
(0,303)\end{array}$ \\
\hline Eficacia Personal & & $\begin{array}{c}2,011^{* * *} \\
(0,287)\end{array}$ & $\begin{array}{c}1,785^{* * *} \\
(0,360)\end{array}$ & $\begin{array}{c}1,991^{* * *} \\
(0,403)\end{array}$ \\
\hline Beneficio & & $\begin{array}{c}0,945^{* * *} \\
(0,220)\end{array}$ & $\begin{array}{c}0,860^{* * *} \\
(0,235)\end{array}$ & $\begin{array}{c}0,356 \\
(0,241)\end{array}$ \\
\hline Coste & & $\begin{array}{c}-0,678^{* *} \\
(0,255)\end{array}$ & $\begin{array}{l}-0,606^{*} \\
(0,263)\end{array}$ & $\begin{array}{l}-0,098 \\
(0,269)\end{array}$ \\
\hline Incentivos de resultado & & & $\begin{array}{c}0,401 \\
(0,259)\end{array}$ & $\begin{array}{l}0,480+ \\
(0,261)\end{array}$ \\
\hline Incentivos de proceso & & & $\begin{array}{c}0,149 \\
(0,310)\end{array}$ & $\begin{array}{l}-0,264 \\
(0,330)\end{array}$ \\
\hline Incentivos ideológicos & & & $\begin{array}{l}-0,057 \\
(0,124)\end{array}$ & $\begin{array}{l}-0,036 \\
(0,118)\end{array}$ \\
\hline Norma social & & & & $\begin{array}{l}-0,481 \\
(0,384)\end{array}$ \\
\hline Motivos altruistas & & & & $\begin{array}{l}-0,529^{*} \\
(0,226)\end{array}$ \\
\hline Eficacia grupal & & & & $\begin{array}{c}0,471 \\
(0,330)\end{array}$ \\
\hline Factor afectivo & & & & $\begin{array}{c}1,765^{* * *} \\
(0,248)\end{array}$ \\
\hline Nuevas Generaciones & $\begin{array}{l}-0,174 \\
(0,110)\end{array}$ & $\begin{array}{c}-0,293^{* *} \\
(0,119)\end{array}$ & $\begin{array}{c}-0,245^{* *} \\
(0,124)\end{array}$ & $\begin{array}{l}-0,076 \\
(0,126)\end{array}$ \\
\hline IU & $\begin{array}{c}0,807^{* * *} \\
(0,115\end{array}$ & $\begin{array}{c}1,201^{* * *} \\
(0,143)\end{array}$ & $\begin{array}{c}1,187^{* * *} \\
(0,158)\end{array}$ & $\begin{array}{c}1,006^{* * *} \\
(0,160)\end{array}$ \\
\hline
\end{tabular}




\begin{tabular}{lcccc}
\hline$\ldots / \ldots$ & $\mathbf{1}$ & $\mathbf{2}$ & $\mathbf{3}$ & $\mathbf{4}$ \\
\hline Constante & $\begin{array}{c}3,406^{* * *} \\
(0,179)\end{array}$ & $\begin{array}{c}1,792^{* * *} \\
(0,319)\end{array}$ & $\begin{array}{c}1,556^{* * *} \\
(0,352)\end{array}$ & $\begin{array}{c}0,578 \\
(0,444)\end{array}$ \\
\hline $\mathrm{R} 2$ & 0,071 & 0,115 & 0,112 & 0,165 \\
\hline $\mathrm{R} 2$ ajus. & 0,068 & 0,109 & 0,103 & 0,154 \\
\hline $\mathrm{F}^{* * *}$ & 19,949 & 18,423 & 12,549 & 14,037 \\
\hline $\mathrm{N}$ & 1565 & 1289 & 1206 & 1151 \\
\hline
\end{tabular}

[*** $\left.\mathrm{p} \leq 0,001 ;{ }^{* *} \mathrm{p} \leq 0,010 ;{ }^{*} \mathrm{p} \leq 0,05 ;+\mathrm{p} \leq 0,10\right]$.

$\dagger$ Las variables independientes están normalizadas $(0-1)$.

Fuente: elaboración propia.

La tabla 4 señala que el modelo de incentivos generales funciona mejor que los dos modelos de elección racional porque la proporción de varianza explicada por él es superior a la obtenida por los otros dos y por las variables asociadas con los recursos individuales. Tal y como indica la literatura, el género, la edad y la clase social ejercen influencia sobre el activismo en el conjunto de la muestra. Los hombres más mayores y de un estatus social más alto son más activos dentro de las formaciones políticas. Destaca la ausencia de significación del nivel educativo sobre la variable dependiente.

En el modelo de elección racional simple (2) y ampliado (3) solo las variables del modelo simple son significativas y se comportan según lo esperado. A medida que aumenta la percepción de la eficacia personal y el beneficio colectivo y disminuyen los costes, aumenta el tiempo dedicado a la participación política. Los incentivos de proceso y resultado no presentan una relación significativa con el activismo en la versión ampliada. En el modelo de incentivos generales (4) solo los incentivos de resultado se comportan según lo esperado. Esto supone que entre los más activos es más probable encontrar a aquellos jóvenes con una presencia más alta de motivaciones orientadas hacia la política como actividad laboral. Los trabajos apuntan que este grupo de afiliados — profesional minded es el más numeroso y el más activo en tanto que están motivados por razones instrumentales (Hooghe et al., 2004; Bruter y Harrison, 2009). La influencia de los incentivos selectivos en los jóvenes en España es más limitada que entre los militantes británicos e irlandeses (Gallagher y Marsh, 2004: 106). En cuanto a la ideología, como era esperado, su influencia es leve: los miembros con una autoubicación más extrema no presentan mayores niveles de actividad.

En el modelo de incentivos generales, la eficacia política, los incentivos de resultado, el factor afectivo y los motivos altruistas ejercen una influencia 
significativa sobre el activismo. Los datos señalan la importancia de la eficacia política personal, que ejerce un efecto positivo y significativo sobre el activismo. El análisis confirma la hipótesis de que los jóvenes con altos niveles de eficacia personal son más activos que aquellos con bajos niveles. En general, aquellos jóvenes que perciben que su contribución puede suponer una diferencia presentan una mayor implicación con la organización juvenil. El factor afectivo impulsa los niveles de activismo; es decir, es más probable encontrar jóvenes más activos entre aquellos que se sienten más identificados con la formación. El comportamiento de esta variable es el esperado y el que se ha observado en los trabajos sobre el Reino Unido e Irlanda (Gallagher et al., 2002: 106).

La norma social y la eficacia política grupal a tenor de lo datos no juegan un rol en la explicación del activismo. Las presiones sociales del contexto cercano al joven podrían incidir en la afiliación de los jóvenes, pero no parecen ejercer influencia sobre el activismo. Esto supone que entre los jóvenes la probabilidad de que sean más o menos activos en la organización juvenil no viene determinada por contextos donde el activismo esté justificado o no ${ }^{10}$.

Por último, hay que señalar que los motivos altruistas también tienen efecto sobre el activismo: son importantes, tienen un efecto significativo, aunque negativo. Por tanto, aquellos jóvenes que expresan un menor imperativo moral presentan una mayor probabilidad de estar involucrados en términos de activismo. Esto supone que esta motivación opera en sentido inverso al esperado en los jóvenes, situación que nos lleva a pensar que el altruismo estaría más vinculado con la entrada en la organización.

En la tabla 5, para cada una de las fuerzas políticas se observa que el modelo de incentivos generales explica un mayor porcentaje de varianza a tenor del R2 ajustado, superior a los modelos de elección racional. La capacidad explicativa de estos, a pesar de ser destacada, es más limitada. Por formaciones políticas los datos señalan diferencias en la influencia de las variables sociodemográficas. Un mayor activismo está presente en los jóvenes socialistas de mayor edad y más presente en ellos que en ellas en el seno de NNGG. En esta última formación, los datos indican que son más activos también aquellos con un elevado nivel educativo. Entre los miembros de las formaciones vinculadas con IU los diferentes modelos sugieren un mayor activismo en los jóvenes con un mayor estatus socioeconómico.

10 Aunque no se muestra en la tabla, se controló por el contexto familiar del joven, introduciendo en el análisis si la familia estaba politizada (es decir, si algún familiar era miembro de un partido, cargo del partido o cargo público). El análisis seńalaba que el crecer en una familia politizada no es un predictor del activismo. El activismo estaría influido por otras externalidades que se encontrarían fuera del contexto familiar. 


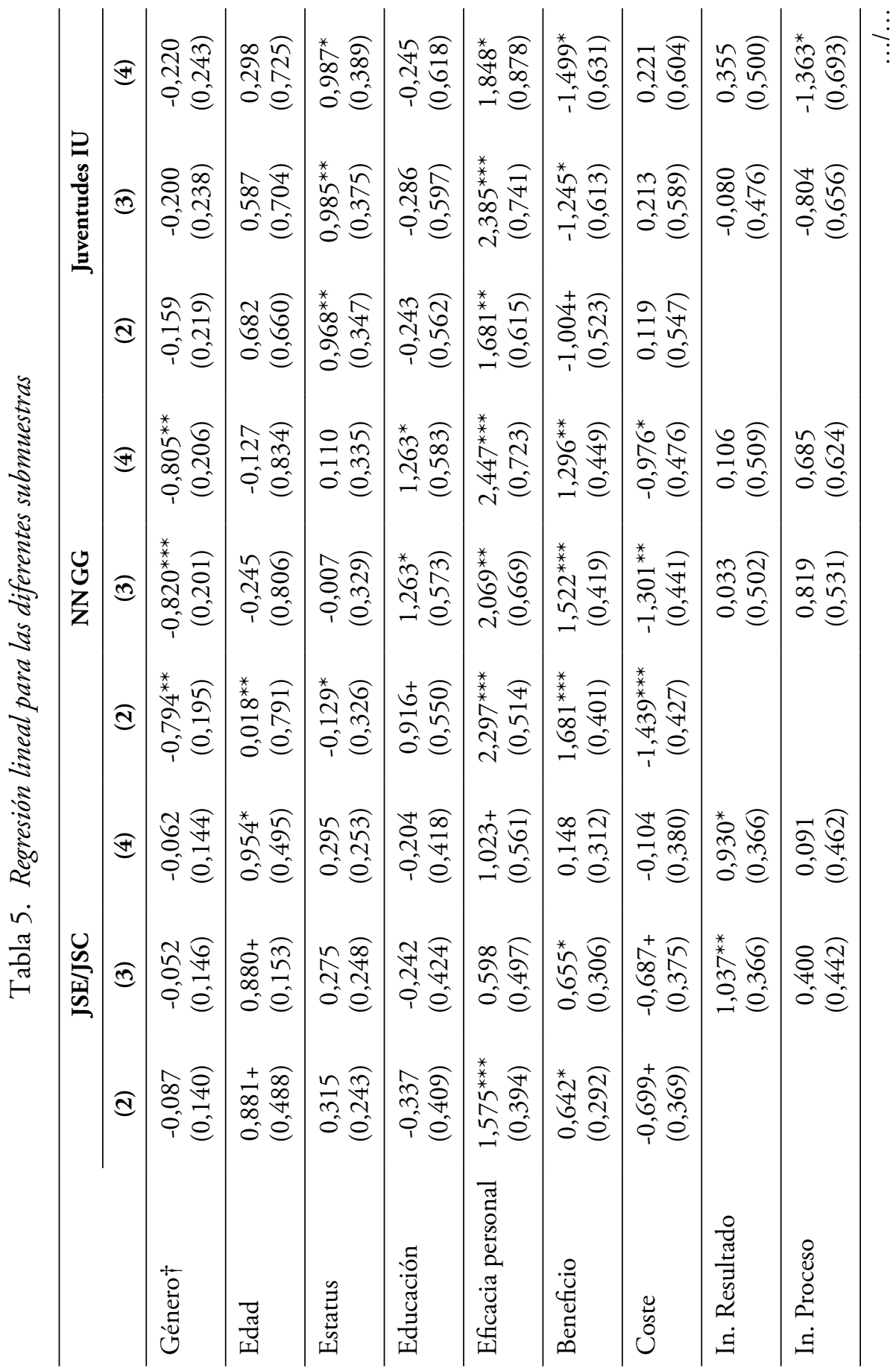




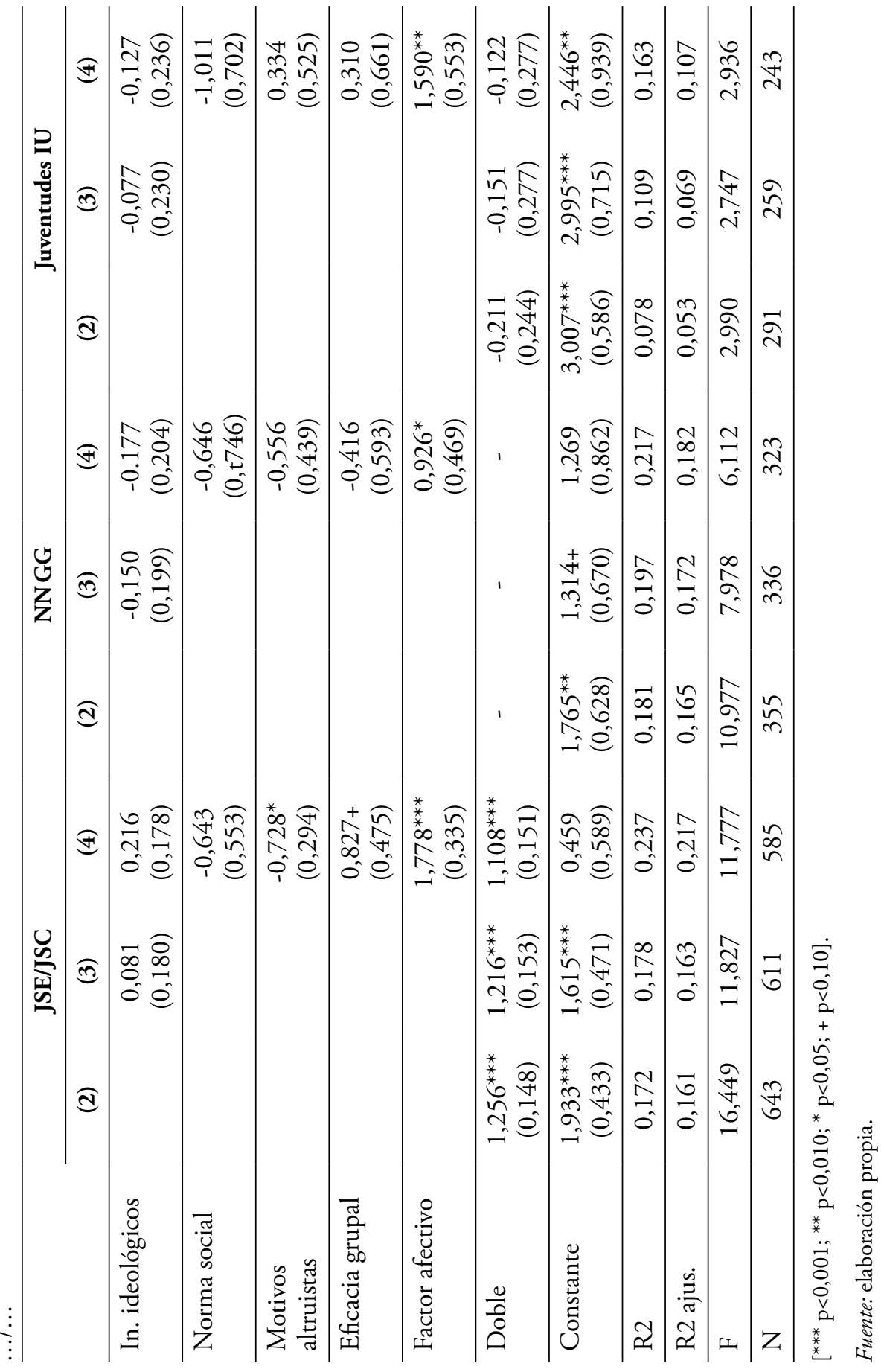


En la organización juvenil socialista el análisis destaca la influencia de la eficacia personal y de los beneficios colectivos en los dos modelos de elección racional. Los beneficios colectivos, al igual que ocurría para la muestra total, pierden su significación en el modelo de incentivos generales. Esta es recogida y ampliada por el factor afectivo, los motivos altruistas, los incentivos de resultado y la eficacia política grupal. En relación con esta última variable hay que indicar que solamente muestra una relación positiva y significativa en esta formación política. Esto supone que el sentido de pertenencia a un grupo, que es percibido como efectivo, es un factor que motiva a los jóvenes socialistas para la participación activa en política. Por otro lado, de entre los incentivos selectivos propuestos por la literatura en la explicación del activismo solo los incentivos de resultado influyen en el activismo. La presencia de estas razones instrumentales —avanzar en su carrera, por ejemplo- motiva la visibilidad de los jóvenes, que busquen contactos con otros miembros y sean más activos, sobre todo entre otros jóvenes que también militan en el partido político (PSOE/PSC). Esto supone que en esta formación los efectos del ciclo de vida al desaparecer con la edad, junto a la presencia de incentivos de resultado por la militancia en ambas organizaciones, confirma el supuesto de encontrar a los más activos entre los profesional minded.

El modelo de incentivos generales realiza un mejor ajuste en los miembros de NNGG (R2 ajustado). Al igual que en los trabajos de Seyd y Whiteley, este porcentaje también es mayor en los conservadores que en los laboristas (Whiteley et al., 1994a, 1994b). Las variables del modelo básico de elección racional son significativas en esta población: el aumento de la eficacia personal, de los beneficios colectivos y de la percepción de bajos costes condicionan los niveles de activismo. Estas tres variables mantienen su influencia en el modelo de elección racional ampliado, mientras que los incentivos de resultado, de proceso e ideológicos carecen de efecto significativo. En el modelo de incentivos generales, ni los tres tipos de incentivos ni la norma social ni los motivos altruistas ni la eficacia grupal ejercen influencia significativa sobre la variable dependiente. El activismo solo se ve influenciado por el factor afectivo, lo que supone encontrar a los más activos entre aquellos miembros que se ven más identificados con NNGG.

$\mathrm{Al}$ igual que en las otras submuestras, la eficacia personal y el beneficio colectivo tienen un efecto significativo sobre el tiempo dedicado a la actividad política en los miembros de las formaciones vinculadas con Izquierda Unida. Este efecto se mantiene en el modelo híbrido de incentivos generales, donde también es significativo el efecto del factor afectivo y de los incentivos de proceso. Sobre estos últimos hay que indicar que estos incentivos selectivos operan en una relación inversa a la esperada, lo que supone que aquellos jóvenes que perciben un menor disfrute en el acto de participación en sí, 
manifiestan una actividad mayor que aquellos que perciben altos valores en este incentivo, compensado por altas dosis de identificación con el grupo.

En general, los dos modelos que parten de la elección racional ven al miembro de la organización política juvenil como un sujeto que toma las decisiones bajo un análisis de los costes y beneficios. Esta propuesta, al introducir la eficacia personal, parece que se acerca bastante a la realidad de los miembros jóvenes de las formaciones políticas. Las variables de la versión básica presentan un mejor ajuste que con la introducción de los incentivos selectivos (véase tabla 4). Pero la introducción de los incentivos no conlleva una explicación más acorde a pesar la importancia que se le ha otorgado para la propia supervivencia de la organización. La ausencia de efecto de los incentivos selectivos entre los jóvenes miembros de los partidos nos hace desplazar la explicación hacia las variables más psicológicas del modelo de incentivos generales, como el factor afectivo. Altos niveles de identificación con un grupo, en este caso etario e ideológico, influyen en la implicación política del joven en su día a día. Esto nos haría pensar en que el joven desarrolla una gran parte de su identidad en relación con ese grupo de iguales que participa en la organización política. Además de esta identificación grupal entre los más activos, en el caso de JSE también nos encontramos que aquellos que perciben una mayor efectividad de la formación política son más activos. Esta situación no ocurre entre los miembros de NNGG y de IU, donde la percepción de la eficacia política grupal también es alta, pero está distribuida de forma más heterogénea entre sus miembros.

Otra de las hipótesis era la importancia de la norma social en la explicación del activismo en la población joven que ha quedado rechazada. Los jóvenes no presentan mayores niveles de activismo por la aprobación de su implicación política por parte de aquellas personas consideradas importantes en el ámbito de la familia y amigos. La norma social no ejerce influencia significativa en el tiempo dedicado a la política en ninguna de las tres submuestras y en su conjunto. Este hecho contrasta con el papel y la significación mostrada en los militantes británicos en los trabajos de Whiteley y Seyd.

\section{CONCLUSIONES}

En un contexto de descenso cuantitativo de pérdida de miembros (Van Biezen et al., 2012) este trabajo aporta conocimiento sobre la implicación política de los jóvenes miembros de los partidos políticos espańoles en el seno de sus organizaciones juveniles. Los datos arrojan unas altas tasas de participación en función del tiempo dedicado a la política. Esto nos lleva a pensar que, a pesar del escaso porcentaje de población juvenil que los integra, su implicación consume mucho tiempo y requiere altos niveles de compromiso, muy superior 
al perfil medio del miembro del partido político, lo que nos hace pensar en una calidad participativa superior en estos jóvenes militantes frente a sus mayores.

El articulo sigue la línea de investigación desarrollada por Seyd y Whiteley (1992) al combinar en el modelo de incentivos generales la explicación conductual e institucional en la explicación del activismo. Además, se valida su propuesta teórica en otros contextos. El modelo de incentivos generales se establece como superior en términos de varianza explicada con los dos modelos de elección racional testados: su poder explicativo en el conjunto de militantes $\mathrm{y}$ en las tres submuestras es mayor.

El trabajo retoma cuatro variables relacionadas con los recursos individuales que muestran la importancia de estos en la explicación del activismo. En general, de entre los jóvenes, los hombres más mayores y de un estatus social más alto muestran altos niveles de activismo. Los dos modelos de elección racional, básico y ampliado, retoman el análisis coste-beneficio, planteando la versión ampliada de que los bienes colectivos, por sí solos, no son suficientes para motivar la participación política. En el caso de los miembros de las organizaciones juveniles, la eficacia personal al percibir su capacidad de poder influir en los beneficios colectivos, sumado a una alta percepción de estos y los bajos costes influyen positivamente en la implicación temporal del joven en el seno de la formación política juvenil.

Hay que señalar por su importancia en la explicación del activismo, como se acaba de señalar, la eficacia política individual. La creencia sobre la propia competencia en la comprensión y participación eficaz en política mantiene un efecto positivo y significativo en las tres fuerzas políticas y en los diferentes modelos analizados. La percepción de la eficacia personal influye de forma significativa en los niveles de activismo entre los miembros de las formaciones políticas juveniles, es decir, en su implicación política, al igual que sucede con el factor afectivo. Aquellos jóvenes que se identifican más con su organización política y que se sienten más identificados con ella muestran mayores niveles de activismo. Esto nos lleva a reconocer a las organizaciones políticas juveniles como un actor con una personalidad propia que vincula en su seno la participación activa de jóvenes con altos niveles de identificación con su grupo. El sentimiento del grupo, de pertenencia a un colectivo, opera muy positivamente sobre el activismo, incluso percibiendo que su efectividad como grupo es muy limitada; es decir, el activismo de los jóvenes estaría más motivado por el factor afectivo, aun a sabiendas de que no conseguirán su objetivo como grupo.

El trabajo también pone de manifiesto que variables que se han considerado de gran importancia para la explicación del activismo, como son los incentivos instrumentales, no son tan importantes como era de esperar. Al igual que ocurre con la norma social, de la que se esperaba un alto impacto sobre el activismo en esta población al encontrarse los jóvenes en un periodo 
de transición hacia otras etapas y ser en algunos casos más dependientes en sus acciones de la aprobación por parte de familia y amigos.

Por último, solo señalar que el comportamiento de los diferentes modelos sobre las variables independientes es muy similar y refuerza la robustez de los resultados obtenidos. Los diferentes modelos mantienen similares comportamientos en cuanto a la explicación general del activismo sobre la variable dependiente a pesar de los cambios que se han podido observar y comentar sobre las variables independientes introducidas.

\section{Bibliografía}

Alarcón, F. J. (2017). El perfil de los miembros de las organizaciones juveniles de los partidos políticos españoles. Revista Española de Ciencia Política, 45, 175-201. Disponible en: https://doi.org/10.21308/recp.45.07.

Aldrich, J. H. (1993). Rational Choice and Turnout. American Journal of Political Science, 37 (1), 246-278. Disponible en: https://doi.org/10.2307/2111531.

Bale, T., Webb, P. y Poletti, M. (2019). Participating Locally and Nationally: Explaining the Offline and Online Activism of British Party Members. Political Studies, 67 (3), 658-675.

Baras, M., Argelaguet, J., y Correa, P. (2010). Radiographie des militans des Partis Politiques en Espagne. Pôle Sud, 33, 65-82. Disponible en: https://doi.org/10.3917/psud.033.0065.

Baras, M., Barberà, O., Barrio, A., Correa, P., y Rodríguez-Teruel, J. (2015). Party Membership in Spain and Congress delegates. En E. van Haute y A. Gauja (eds.). Party Members and Activists (pp. 17-33). Oxon: Routledge.

Bargel, L. y Dechezelles, S. (2009). L'engagement dans des partis politiques de droite. Revue française de science politique, 59 (1), 5-6. Disponible en: https://doi.org/10.3917/rfsp.591.0005.

Bruter, M. y Harrison, S. (2009). The future of our Democracies: Young party member in Europe. Basingstoke: Palgrave Macmillan. Disponible en: https://doi.org/10.1057/9780230245426.

Campbell, B. A. (1980). A Theoretical Approach to Peer Influence in Adolescence Socialization. American Journal of Political Science, 24 (2), 324-344. Disponible en: https://doi. org/10.2307/2110868.

Clark, B. y Wilson, J. Q. (1961). Incentives systems: a theory of organizations. Administrative Science Quarterly, 6 (2), 129-166. Disponible en: https://doi.org/10.2307/2390752.

Clarke, H. y Acock, A. C. (1989). National elections and political attitudes: The case of political efficacy. British Journal of Political Science, 19 (4), 551-562. Disponible en: https:// doi.org/10.1017/S0007123400005639.

Clarke, H., Price, R., Stewart, M. y Krause, R. (1978). Motivational Patterns and Differential Participation in a Canadian Party: The Ontario Liberals. American Journal of Political Science, 22 (1), 130-151. Disponible en: https://doi.org/10.2307/2110672.

Cross, W. y Young, L. (2004). The contours of political party membership in Canada. Party Politics, 10 (4), 427-444. Disponible en: https://doi.org/10.1177/1354068804043907.

Cross, W. y Young, L. (2008). Activism Among Young Party Members: The Case of the Canadian Liberal Party. Journal of Elections, Public Opinion and Parties, 18 (3), 257-281. Disponible en: https://doi.org/10.1080/17457280802227660. 
Downs, A. (1957). An Economic Theory of democracy. New York: Harper and Bros.

Espinoza, V. y Madrid, S. (2010). Trayectoria y eficacia policia de los militantes en juventudes politicas. Estudio de la élite política emergente. Chile: Andros.

Eulau, H., Buchanan, W., Ferguson, L. y Wahlke, J. (1959). The political Socialization of American State legislators. Midwest Journal of Political Science, 3 (2), 188-206. Disponible en: https://doi.org/10.2307/2108909.

Gallagher, M. y Marsh, M. (2004). Party Membership in Ireland: The Members of Fine Gael. Party Politics, 10 (4), 407-425. Disponible en: https://doi.org/10.1177/1354068804043906.

Gallagher, M., Liston, V. Marsh, M. y Weeks, L. (2002). Explaining activism levels among Fine Gael members: a test of the general incentives model. Irish Political Studies, 17, 97-113. Disponible en: https://doi.org/10.1080/714003142.

Heidar, K. y Saglie, J. (2003). A Decline of Linkage? Intra-party Participation in Norway, 1991-2000. European Journal of Political Research, 42, 761-786. Disponible en: https:// doi.org/10.1111/1475-6765.00103.

Hooghe, M. y Dassonnneville, R. (2013). Voters and Candidates of the Future: The Intention of Electoral Participation among Adolescents in 22 European Countries. Young, Nordic Journal of Youth Research, 21 (1), 1-28. Disponible en: https://doi. org/10.1177/1103308812467664.

Hooghe, M., Stolle, D. y P. Stouthuysen (2004). Head Start in Politics: The recruitment function of youth organizations of political parties in Belgium (Flanders). Party Politics, 10 (2),193-212. Disponible en: https://doi.org/10.1177/1354068804040503.

May, J. (1973). Opinion Structure of Political Parties: The Special Law of curvilinear Disparity. PoliticalStudies, 21 (2), 135-151. Disponible en: https://doi.org/10.1111/j.1467-9248.1973. tb01423.x.

Olson, M. (1965). The logic of Collective Action. Public Goods and the Theory of Groups. Cambrigde: Havard University Press.

Panebianco, A. (1990). Modelos de partido, organización y poder en los partidos políticos. Madrid: Alianza.

Pattie, C., Seyd, P. y Whiteley, P. (2004). Citizenship, Democracy and Participation in Contemporary Britain. Cambridge: Cambridge University Press. Disponible en: https://doi. org/10.1017/CBO9780511490811.

Pedersen, K., Bille, L., Buch, R., Elklit, J., Hansen, B. y Nielsen, H. J. (2004). Sleeping or Active Partners? Danish Party Members at the Turn of the Millennium. Party Politics, 10 (4), 367-384. Disponible en: https://doi.org/10.1177/1354068804043904.

Poletti, M., Paul Webb, P. y Bale, T. (2019). Why do only some people support parties actually join them? Evidence from Britain. West European Politics, 42 (1), 156-172. Disponible en: https://doi.org/10.1080/01402382.2018.1479921.

Rainsford, E. (2018). UK Political Parties' Youth Factions: A Glance at the Future of Political Parties. Parliamentary Affairs, 71 (4), 783-803. Disponible en: https://doi.org/10.1093/ $\mathrm{pa} / \mathrm{gsx} 040$.

Scarrow, S. (2015). Beyond Party Members: Changing Approaches to Partisan Mobilization. New York: Oxford University Press. Disponible en: https://doi.org/10.1093/acprof:oso/9780199661862.001.0001. 
Scarrow, S. y Gezgor, B. (2010). Declining memberships, changing members? European political members in new era. Party Politics, 16 (6), 823-843. Disponible en: https://doi. org/10.1177/1354068809346078.

Seyd, P. y Whiteley, P. (1992). Labour's grass roots. The politics of party membership. Oxford: Clarendon Press.

Seyd, P. y Whiteley, P. (2002). New Labour's Grassroots: The Transformation of the Labour Party Membership. Basingstoke: Palgrave-Macmillan. Disponible en: https://doi.org/10.1057/ 9780230599215.

Smith, P. (1970). Political Involvement: A Case Study of Urban Party Activists [tesis doctoral]. McMaster Univesity, Mimeo.

Van Biezen I., Mair, P. y Poguntke T. (2012). Going, going, ...gone? The decline of party membership in contemporary Europe. European Journal of Political Research, 51 (1), 24-56. Disponible en: https://doi.org/10.1111/j.1475-6765.2011.01995.x.

Van Haute, E. (2011). Who voices? Socialisation process and ideological profile of discontented party members. En E. Van Haute (ed.). Party Membership in Europe: Exploration into the anthills of party politics. Brussels: Editions de l'Université de Bruxelles. Disponible en: https://doi.org/10.1177/1354068810395058.

Van Haute, E. (2015). Party membership in Belgium: form the cradle to the grave? En E. van Haute y A. Gauja (eds.). Party Members and Activists (p. 34). Oxon: Routledge.

Van Haute, E. y Gauja, A. (eds.) (2015). Party Members and Activists. Oxon: Routledge. Disponible en: https://doi.org/10.4324/9781315722214.

Verba, S., Schlozman, K. L. y Brady, H. (1995). Voice and Equality. Civic Voluntarism in American Politics. Cambridge: Harvard University Press.

Weber, R. (2018). Why do young people join parties? The influence of individual resources on motivation. Party Politics, 26 (4), 496-509. Disponible en: https://doi.org/10.1177/ 1354068818792576.

Whiteley, P. y Seyd, P. (1996). Rationality and Party activism: encompassing test of alternative models of political participation. European Journal of Political Research, 29 (2), 339-371. Disponible en: https://doi.org/10.1111/j.1475-6765.1996.tb00649.x.

Whiteley, P. y Seyd, P. (2002). High intensity participation. The dynamics of Party activism in Britain. Ann Arbor: University Michigan. Disponible en: https://doi.org/10.3998/ mpub.14704.

Whiteley, P. y Seyd, P. y Billinghurst, A. (2006). Third Force Politics: Liberal Democrats at the Grassroots. Oxford: Oxford University Press. Disponible en: https://doi.org/10.1093/01 99242828.001 .0001$.

Whiteley, P. y Seyd, P. y Richardson, J. (1994a). True Blues: The Politics of Conservative Party Membership. Oxford: Oxford University Press.

Whiteley, P. y Seyd, P. y Bissell P. (1994b). Explaining party activism: The case of the British Conservative Party. British Journal of Political Science, 24 (1), 79-94. Disponible en: https://doi.org/10.1017/S0007123400006797.

Young, L. y Cross, W. (2002). Incentives to Membership in Canadian Political Parties. Political Research Quarterly, 55 (3), 547-569. Disponible en: https://doi.org/10.1177/10659129 0205500303. 


\section{ANEXO. DESCRIPTIVOS DE LAS VARIABLES UTILIZADAS EN LOS MODELOS DE REGRESIÓN EN LA MUESTRA TOTAL Y SUBMUESTRAS}

\begin{tabular}{|c|c|c|c|c|}
\hline & JSE/JSC & NNGG & $\begin{array}{c}\text { Juventudes } \\
\text { IU }\end{array}$ & Total \\
\hline \multicolumn{5}{|l|}{ Tiempo } \\
\hline Rango & $0-7$ & $0-7$ & $0-7$ & $0-7$ \\
\hline Media & 4,08 & 3,79 & 4,9 & 4,19 \\
\hline Desviación típica & 1,902 & 1,848 & 1,654 & 1,876 \\
\hline \multicolumn{5}{|c|}{ Variables independientes (normalizadas, rango 0-1) } \\
\hline \multicolumn{5}{|c|}{ Género $($ mujer $=1)$} \\
\hline Media & 0,40 & 0,36 & 0,28 & 0,36 \\
\hline Desviación típica & 0,491 & 0,481 & 0,449 & 0,481 \\
\hline \multicolumn{5}{|l|}{ Edad } \\
\hline Media & 0,44 & 0,37 & 0,39 & 0,41 \\
\hline Desviación típica & 0,181 & 0,127 & 0,187 & 0,172 \\
\hline \multicolumn{5}{|l|}{ Estatus social } \\
\hline Media & 0,69 & 0,70 & 0,71 & 0,70 \\
\hline Desviación típica & 0,288 & 0,286 & 0,281 & 0,212 \\
\hline \multicolumn{5}{|l|}{ Educación } \\
\hline Media & 0,53 & 0,50 & 0,49 & 0,51 \\
\hline Desviación típica & 0,218 & 0,189 & 0,223 & 0,212 \\
\hline \multicolumn{5}{|c|}{ Eficacia política individual } \\
\hline Media & 0,73 & 0,74 & 0,70 & 0,73 \\
\hline Desviación típica & 0,172 & 0,185 & 0,160 & 0,174 \\
\hline \multicolumn{5}{|c|}{ Beneficio colectivo } \\
\hline Media & 0,56 & 0,62 & 0,43 & 0,55 \\
\hline Desviación típica & 0,206 & 0,229 & 0,152 & 0,213 \\
\hline \multicolumn{5}{|l|}{ Coste } \\
\hline Media & 0,54 & 0,53 & 0,61 & 0,55 \\
\hline Desviación típica & 0,194 & 0,210 & 0,181 & 0,198 \\
\hline
\end{tabular}




\begin{tabular}{|c|c|c|c|c|}
\hline & JSE/JSC & NNGG & $\begin{array}{c}\text { Juventudes } \\
\text { IU }\end{array}$ & Total \\
\hline \multicolumn{5}{|c|}{ Incentivos de resultado } \\
\hline Media & 0,69 & 0,71 & 0,51 & 0,66 \\
\hline Desviación típica & 0,228 & 0,222 & 0,239 & 0,242 \\
\hline \multicolumn{5}{|c|}{ Incentivos de proceso } \\
\hline Media & 0,65 & 0,66 & 0,58 & 0,64 \\
\hline Desviación típica & 0,180 & 0,201 & 0,178 & 0,188 \\
\hline \multicolumn{5}{|c|}{ Incentivos ideológicos } \\
\hline Media & 0,19 & 0,33 & 0,30 & 0,25 \\
\hline Desviación típica & 0,395 & 0,473 & 0,461 & 0,438 \\
\hline \multicolumn{5}{|l|}{ Norma social } \\
\hline Media & 0,44 & 0,43 & 0,47 & 0,45 \\
\hline Desviación típica & 0,127 & 0,127 & 0,143 & 0,131 \\
\hline \multicolumn{5}{|l|}{ Motivos altruistas } \\
\hline Media & 0,78 & 0,74 & 0,83 & 0,78 \\
\hline Desviación típica & 0,277 & 0,267 & 0,265 & 0,274 \\
\hline \multicolumn{5}{|c|}{ Eficacia política grupal } \\
\hline Media & 0,70 & 0,66 & 0,63 & 0,68 \\
\hline Desviación típica & 0,165 & 0,195 & 0,173 & 0,177 \\
\hline \multicolumn{5}{|l|}{ Factor afectivo } \\
\hline Media & 0,71 & 0,68 & 0,78 & 0,72 \\
\hline Desviación típica & 0,221 & 0,241 & 0,197 & 0,224 \\
\hline
\end{tabular}

Fuente: elaboración propia. 